\title{
Stability Analysis of one Prey and Two Predators Model
}

\author{
B. Sita Ram Babu , Paparao. A. V , N. V. S. R. C. Murty Gamini
}

\begin{abstract}
We projected a 3 species Ecological model with a Prey and 2 predators. Distributed kind of delay is incorporated within the interaction of prey and second predator is taken for investigation. The system dynamics is studied at its interior equilibrium purpose with exponential kind of delay kernels. The impact of your time delay on the energising behavior of the system is studied exploitation Numerical simulation. it's shown that the delay arguments with totally different delay parameters exhibit wealthy dynamics.
\end{abstract}

Keywords: co-existing state, local stability, global stability, Time delay, Numerical simulation.

\section{INTRODUCTION}

Mathematical modeling in Ecology gains importance in recent decades. The stability analysis of ecosystems is quite intersecting and complex in nature. Differential equations are widely used in the stability analysis. Braun [8] and Simon's [9] explain the applications of differential equations in this area. Lokta [1] and Volterra [2] studied the different models in population ecology.Kapur [3, 4] discussed the models in biology, medicine, epidemiology, ecology etc. May [5], Freedman [6],Paul colinvaux [7] contributed a lot to this field. Time delays are natural in ecological phenomenon. The stability analysis of time delay models are widely explained by Cushing, J.M [10], Sreehari Rao [11], Gopalaswamy.K[12]. Time delay in interactions in three species models with a prey, predator and competitor models with two predator model is taken for investigation. The model is represented by system of integro-differential equations and system dynamics is studied at co-existing state. Numerical simulation is allotted in support of stability analysis using MAT lab simulation.

\section{MATHEMATICAL MODEL}

A three species ecological model with a single prey and two predators are considered for investigation. Two predators namely first predator $\left(N_{2}\right)$, second predator $\left(N_{3}\right)$ are competing for the same prey $\left(N_{1}\right)$. A time delay is introduced in the interaction of prey and second predator (Gestation period of the prey) .Death rates of three

Revised Version Manuscript Received on 16 September, 2019

B. Sitarambabu, Department of MathematicsVidya Jyothi Institute of Technology, Hyd-500075,T.G,India..

Papa Rao A. V., Department of Mathematics, JNTUK,

UCE Vizianagaram-535003, A.P, India

Amalapuram-533201, E.G.Dt., A.P., India. are discussed by paparao [13-17]. In spite of that a single prey

N. V. S. R. C. Murthy, Department of S\&H, BVCITS, Batlapalem

populations are also considered for investigation.Keeping the above aspects in view, the model is characterized by the following system of integro- differential equations.

$$
\begin{aligned}
& \frac{d N_{1}}{d t}=a_{1} N_{1}-\alpha_{11} N_{1}^{2}-\alpha_{12} N_{1} N_{2}-\alpha_{13} N_{1} \int_{-\infty}^{t} k_{1}(t-u) N_{3}(u) d u-d_{1} N_{1} \\
& \frac{d N_{2}}{d t}=a_{2} N_{2}-\alpha_{22} N_{2}^{2}+\alpha_{21} N_{2} N_{1}-\alpha_{23} N_{2} N_{3}-d_{2} N_{2} \\
& \frac{d N_{3}}{d t}=a_{3} N_{3}-\alpha_{33} N_{3}^{2}+\alpha_{31} N_{3} \int_{-\infty}^{t} k_{2}(t-u) N_{1}(u) d u-\alpha_{32} N_{2} N_{3}-d_{3} N_{3} \\
& (2.1)
\end{aligned}
$$

\begin{tabular}{|c|c|c|}
\hline S.No & Dor & \\
\hline 1 & $\begin{array}{l}N_{1}, N_{2} \\
\& N_{3}\end{array}$ & $\begin{array}{l}\text { Population strengths of three } \\
\text { populations (prey, first } \\
\text { predator and second predator) } \\
\text { respectively }\end{array}$ \\
\hline 2 & $a_{1}, a_{2}, a_{3}$ & $\begin{array}{l}\text { Growths rates of three } \\
\text { populations }\end{array}$ \\
\hline 3 & $\begin{array}{l}\alpha_{i i} \\
(i=1,2,3)\end{array}$ & $\begin{array}{l}\text { Inter species competitions } \\
\text { rates of three species } \\
\text { (negative values) }\end{array}$ \\
\hline 4 & $\alpha_{12}$ & $\begin{array}{l}\text { Prey and first predator } \\
\text { interaction rate ( negative } \\
\text { value) }\end{array}$ \\
\hline 5 & $\alpha_{21}$ & $\begin{array}{l}\text { First predator and prey } \\
\text { interaction rate ( positive } \\
\text { value) }\end{array}$ \\
\hline 6 & $\alpha_{23}$ & $\begin{array}{l}\text { First and second predators } \\
\text { interaction rate (negative } \\
\text { value) }\end{array}$ \\
\hline 7 & $\alpha_{32}$ & $\begin{array}{l}\text { Second and first predators } \\
\text { interaction rate (negative } \\
\text { value) }\end{array}$ \\
\hline 7 & $\alpha_{13}$ & $\begin{array}{l}\text { Prey and second predator } \\
\text { interaction rate (negative } \\
\text { value) }\end{array}$ \\
\hline 9 & $\alpha_{31}$ & $\begin{array}{l}\text { Second predator and prey } \\
\text { interaction rate (positive } \\
\text { value) }\end{array}$ \\
\hline 10 & $\mathrm{~d}_{1}, \mathrm{~d}_{2}, \mathrm{~d}_{3}$ & $\begin{array}{l}\text { Death rates of three } \\
\text { populations }\end{array}$ \\
\hline 11 & $\begin{array}{l}k_{1}(t-u) \& \\
k_{2}(t-u)\end{array}$ & kernel weights \\
\hline
\end{tabular}

Where the parameters in the above model is described as follows

Put $\mathrm{t}-\mathrm{u}=\mathrm{z}$, we get the following system of equations 


\section{Stability analysis of one Prey and Two Predators Model}

$\frac{d N_{1}}{d t}=a_{1} N_{1}-\alpha_{11} N_{1}^{2}-\alpha_{12} N_{1} N_{2}-\alpha_{13} N_{1} \int_{0}^{\infty} k_{1}(z) N_{3}(t-z) d z-d_{1} N_{1}$

$\frac{d N_{2}}{d t}=a_{2} N_{2}-\alpha_{22} N_{2}^{2}+\alpha_{21} N_{2} N_{1}-\alpha_{23} N_{2} N_{3}-d_{2} N_{2}$

$\frac{d N_{3}}{d t}=a_{3} N_{3}-\alpha_{33} N_{3}^{2}+\alpha_{31} N_{3} \int_{0}^{\infty} k_{2}(z) N_{1}(t-z) d z-\alpha_{32} N_{2} N_{3}-d_{3} N_{3}$

$b_{1}=\left(\alpha_{11} \overline{N_{1}}+\alpha_{22} \overline{N_{2}}+\alpha_{33} \overline{N_{3}}\right)>0$

(2.2)

Kernels can be chosen of exponential type

\section{EQUILIBRIUM STATES:}

Solving the system of equations (2.1) by equating to zero we get the equilibrium point is given by

\section{$\mathbf{E}_{\mathbf{1}}$ : Co-existing state}

$\bar{N}_{1}=\frac{\left(a_{1}-d_{1}\right)\left(\alpha_{22} \alpha_{33}-\alpha_{23} \alpha_{32}\right)+\left(a_{2}-d_{2}\right)\left(\alpha_{13} \alpha_{32}-\alpha_{12} \alpha_{33}\right)+\left(a_{3}-d_{3}\right)\left(\alpha_{12} \alpha_{23}-\alpha_{13} \alpha_{22}\right)}{\alpha_{11}\left(\alpha_{22} \alpha_{33}-\alpha_{23} \alpha_{32}\right)+\alpha_{12}\left(\alpha_{21} \alpha_{33}-\alpha_{31} \alpha_{23}\right)+\alpha_{13}\left(\alpha_{31} \alpha_{22}-\alpha_{21} \alpha_{32}\right)}$ By algebraic calculations

$\left(b_{1} b_{2}-b_{3}\right)=\left(\alpha_{11}^{2} \alpha_{22}+\alpha_{11} \alpha_{12} \alpha_{21}\right) \bar{N}_{1}^{2} \bar{N}_{2}+\left(\alpha_{11}^{2} \alpha_{33}+\alpha_{11} \alpha_{13} \alpha_{31} k_{1}(\lambda) k_{2}(\lambda)\right) \bar{N}_{1}^{2} \bar{N}_{3}$

$$
\begin{aligned}
& +\left(\alpha_{22}{ }^{2} \alpha_{33}-\alpha_{22} \alpha_{23} \alpha_{32}\right) \bar{N}_{2}^{2} \bar{N}_{3}+\left(\alpha_{22}{ }^{2} \alpha_{11}+\alpha_{22} \alpha_{12} \alpha_{21}\right) \bar{N}_{2}{ }^{2} \bar{N}_{1} \\
& +\left(\alpha_{11} \alpha_{33}{ }^{2}+\alpha_{33} \alpha_{13} \alpha_{31} k_{1}(\lambda) k_{2}(\lambda) \bar{N}_{3}^{2} \bar{N}_{1}+\left(\alpha_{22} \alpha_{33}{ }^{2}-\alpha_{33} \alpha_{23} \alpha_{32}\right) \bar{N}_{2} \bar{N}_{3}^{2}\right. \\
& +\overline{N_{1}} \bar{N}_{2} \bar{N}_{3}\left(2 \alpha_{11} \alpha_{22} \alpha_{33}+\alpha_{12} \alpha_{23} \alpha_{31} k_{2}(\lambda)+\alpha_{13} \alpha_{21} \alpha_{32} k_{1}(\lambda)\right)
\end{aligned}
$$

$\left(b_{1} b_{2}-b_{3}\right)>0$ (Majority of the terms are positive)

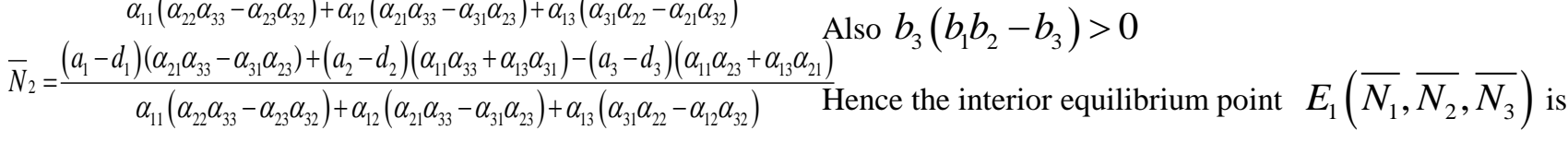

$\bar{N}_{3}=\frac{\left(a_{1}-d_{1}\right)\left(\alpha_{22} \alpha_{31}-\alpha_{21} \alpha_{32}\right)-\left(a_{2}-d_{2}\right)\left(\alpha_{11} \alpha_{32}+\alpha_{12} \alpha_{31}\right)+\left(a_{3}-d_{3}\right)\left(\alpha_{11} \alpha_{22}+\alpha_{12} \alpha_{21}\right)}{\alpha_{11}\left(\alpha_{22} \alpha_{33}-\alpha_{23} \alpha_{32}\right)+\alpha_{12}\left(\alpha_{21} \alpha_{33}-\alpha_{31} \alpha_{23}\right)+\alpha_{13}\left(\alpha_{31} \alpha_{22}-\alpha_{12} \alpha_{32}\right)}$ locally asymptotically stable

This equilibrium state exist only when,

$\bar{N}_{1}>0, \bar{N}_{2} \Rightarrow 0, \bar{N}_{3}>0$

\section{STABILITY OF THE EQUILIBRIUM POINT E1:}

Theorem: The interior equilibrium point $E_{1}\left(\overline{N_{1}}, \overline{N_{2}}, \overline{N_{3}}\right)$ is locally asymptotically stable

Proof: Let the variational matrix is given by

$J=\left[\begin{array}{ccc}-\alpha_{11} \bar{N}_{1} & -\alpha_{12} \overline{N_{1}} & -\alpha_{13} \bar{N}_{1} k_{1}^{*}(\lambda) \\ \alpha_{21} \overline{N_{2}} & -\alpha_{22} \overline{N_{2}} & -\alpha_{23} \overline{N_{2}} \\ \alpha_{31} \overline{N_{3}} k_{2}^{*}(\lambda) & -\alpha_{32} \overline{N_{3}} & -\alpha_{33} \overline{N_{3}}\end{array}\right]$

With The characteristic equation $\lambda^{3}+b_{1} \lambda^{2}+b_{2} \lambda+b_{3}=0$

Where

$$
\begin{aligned}
& b_{1}=\left(\alpha_{11} \overline{N_{1}}+\alpha_{22} \overline{N_{2}}+\alpha_{33} \overline{N_{3}}\right) \\
& b_{2}=\left(\alpha_{11} \alpha_{22}+\alpha_{12} \alpha_{21}\right) \overline{N_{1}} \overline{N_{2}}+ \\
& \left(\alpha_{11} \alpha_{33}+\alpha_{13} \alpha_{31} k_{1}(\lambda) k_{2}(\lambda)\right) \overline{N_{1}} \overline{N_{3}} \\
& +\left(\alpha_{22} \alpha_{33}-\alpha_{23} \alpha_{32}\right) \overline{N_{2}} \overline{N_{3}} \\
& b_{3}=\overline{N_{1}} \overline{N_{2}} \overline{N_{3}}\left(\begin{array}{l}
\alpha_{11} \alpha_{22} \alpha_{33}+\alpha_{12} \alpha_{21} \alpha_{33} \\
+\alpha_{13} \alpha_{22} \alpha_{31} k_{1}(\lambda) k_{2}(\lambda) \\
-\alpha_{11} \alpha_{23} \alpha_{32}-\alpha_{12} \alpha_{23} \alpha_{31} k_{2}(\lambda) \\
-\alpha_{13} \alpha_{21} \alpha_{32} k_{1}(\lambda)
\end{array}\right)
\end{aligned}
$$

By Routh-Hurwitz criteria, the system is stable if $b_{1}>0$, $\left(b_{1} b_{2}-b_{3}\right)>0$ and $b_{3}\left(b_{1} b_{2}-b_{3}\right)>0$.

\section{Clearly}

\section{Global stability}

Theorem: Theinterior equilibrium point $E_{1}\left(\overline{N_{1}}, \overline{N_{2}}, \overline{N_{3}}\right)$ is globally asymptotically stable

Proof: Let the Lyapunov function be

$V\left(N_{1}, N_{2}, N_{3}\right)=\sum_{i=1}^{3} N_{i}-\overline{N_{i}}-\overline{N_{i}} \log \left(\frac{N_{i}}{\overline{N_{i}}}\right)$

$+\frac{1}{2} \alpha_{13} \int_{0}^{\infty} k_{1}(z) \int_{t-z}^{t}\left[N_{3}-\overline{N_{3}}\right]^{2} d u d z$

$+\frac{1}{2} \alpha_{31} \int_{0}^{\infty} k_{2}(z) \int_{t-z}^{t}\left[N_{1}-\overline{N_{1}}\right]^{2} d u d z$

The time derivate of ' $\mathrm{V}$ ' along the solutions of equations (2.1) is

$V^{1}(t)=\sum_{i=1}^{3} \frac{\left[N_{i}-\overline{N_{i}}\right]}{N_{i}} N_{i}^{1}$

$+\frac{1}{2} \alpha_{13} \int_{0}^{\infty} k_{1}(z)\left[N_{3}-\overline{N_{3}}\right]^{2} d z$

$-\frac{1}{2} \alpha_{13} \int_{0}^{\infty} k_{1}(z)\left[N_{3}(t-z)-\overline{N_{3}}\right]^{2} d z$

$+\frac{1}{2} \alpha_{31} \int_{0}^{\infty} k_{2}(z)\left[N_{1}-\overline{N_{1}}\right]^{2} d z$

$-\frac{1}{2} \alpha_{31} \int_{0}^{\infty} k_{2}(z)\left[N_{1}(t-z)-\overline{N_{1}}\right]^{2} d z$

From the equation (2.1) we have 


$$
\begin{aligned}
& V^{1}(t)=\left[N_{1}-\overline{N_{1}}\right]\left(\begin{array}{l}
a_{1}-\alpha_{11} N_{1}-\alpha_{12} N_{2} \\
-\alpha_{13} \int_{0}^{\infty} k_{1}(z) N_{3}(t-z) d z-d_{1}
\end{array}\right) \\
& +\left[N_{2}-\overline{N_{2}}\right]\left(\begin{array}{l}
a_{2}-\alpha_{22} N_{2} \\
+\alpha_{21} N_{1}-\alpha_{23} N_{3}-d_{2}
\end{array}\right) \\
& +\left[N_{3}-\overline{N_{3}}\right]\left(\begin{array}{l}
a_{3}-\alpha_{32} N_{3} \\
+\alpha_{31} \int_{0}^{\infty} k_{2}(z) N_{1}(t-z) d z-\alpha_{32} N_{2}-d_{3}
\end{array}\right) \\
& +\frac{1}{2} \alpha_{31}\left[N_{1}-\overline{N_{1}}\right]^{2} \\
& +\frac{1}{2} \alpha_{13}\left[N_{3}-\overline{N_{3}}\right]^{2} \\
& -\frac{1}{2} \alpha_{13} \int_{0}^{\infty} k_{1}(z)\left[N_{3}(t-z)-\overline{N_{3}}\right]^{2} d z \\
& -\frac{1}{2} \alpha_{31} \int_{0}^{\infty} k_{2}(z)\left[N_{1}(t-z)-\overline{N_{1}}\right]^{2} d z
\end{aligned}
$$

By proper choice of $a_{1}, a_{2} \& a_{3}$

$$
\begin{aligned}
& a_{1}=\alpha_{11} \overline{N_{1}}+\alpha_{12} \overline{N_{2}} \\
& +\alpha_{13} \int_{0}^{\infty} k_{2}(z) N_{3}(t-z) d z+d_{1} \\
& a_{2}=-\alpha_{21} \bar{N}_{1}+\alpha_{22} \overline{N_{2}} \\
& +\alpha_{23} \overline{N_{3}}+d_{2} \\
& \& a_{3}=-\alpha_{31} \int_{0}^{\infty} k_{2}(z) N_{1}(t-z) d z \\
& +\alpha_{33} \overline{N_{3}}+\alpha_{32} \bar{N}_{2}+d_{3} \\
& =-\alpha_{11}\left(N_{1}-\overline{N_{1}}\right)^{2}-\alpha_{22}\left(N_{2}-\overline{N_{2}}\right)^{2} \\
& -\alpha_{33}\left(N_{3}-\overline{N_{3}}\right)^{2} \\
& -\left(\alpha_{32}+\alpha_{23}\right)\left(N_{2}-\overline{N_{2}}\right)\left(N_{3}-\overline{N_{3}}\right)^{2} \\
& +\left(\alpha_{21}-\alpha_{12}\right)\left(N_{2}-\overline{N_{2}}\right)\left(N_{1}-\overline{N_{1}}\right) \\
& +\frac{1}{2} \alpha_{31}\left[N_{1}-\overline{N_{1}}\right]^{2}+\frac{1}{2} \alpha_{13}\left[N_{3}-\overline{N_{3}}\right]^{2} \\
& -\frac{1}{2} \alpha_{13} \int_{0}^{\infty} k_{1}(z)\left[N_{3}(t-z)-\overline{N_{3}}\right]^{2} d z \\
& -\frac{1}{2} \alpha_{31} \int_{0}^{\infty} k_{2}(z)\left[N_{2}(t-z)-\overline{N_{2}}\right]^{2} d z
\end{aligned}
$$

Using the

$a b \leq \frac{a^{2}+b^{2}}{2}$,

$\int_{0}^{\infty} k_{1}(z)\left[N_{3}(t-z)-\overline{N_{3}}\right]^{2} \leq \int_{0}^{\infty} k_{1}(z) d z=1$

$\int_{0}^{\infty} k_{2}(z)\left[N_{2}(t-z)-\overline{N_{2}}\right]^{2} \leq \int_{0}^{\infty} k_{2}(z) d z=1$,

$$
\begin{aligned}
& =-\alpha_{11}\left(N_{1}-\overline{N_{1}}\right)^{2}-\alpha_{22}\left(N_{2}-\overline{N_{2}}\right)^{2} \\
& -\alpha_{33}\left(N_{3}-\overline{N_{3}}\right)^{2} \\
& -\frac{\left(\alpha_{32}+\alpha_{23}\right)}{2}\left[\left(N_{2}-\overline{N_{2}}\right)^{2}+\left(N_{3}-\overline{N_{3}}\right)^{2}\right] \\
& +\frac{1}{2} \alpha_{31}\left[N_{1}-\overline{N_{1}}\right]^{2} \\
& +\frac{1}{2} \alpha_{13}\left[N_{3}-\overline{N_{3}}\right]^{2} \\
& +\frac{\left(\alpha_{21}-\alpha_{12}\right)}{2}\left[\left(N_{2}-\overline{N_{2}}\right)^{2}+\left(N_{1}-\overline{N_{1}}\right)^{2}\right] \\
& -\frac{1}{2}\left(\alpha_{31}+\alpha_{13}\right) \\
& \leq-\left\|\left(\alpha_{11}+\frac{1}{2} \alpha_{31}+\frac{1}{2} \alpha_{21}-\frac{1}{2} \alpha_{12}\right)\right\|\left(N_{1}-\overline{N_{1}}\right)^{2} \\
& -\left\|\left(\alpha_{22}-\frac{1}{2} \alpha_{12}+\frac{1}{2} \alpha_{21}-\frac{1}{2} \alpha_{32}-\frac{1}{2} \alpha_{23}\right)\right\|\left(N_{2}-\overline{N_{2}}\right)^{2} \\
& -\left\|\left(\alpha_{33}+\frac{1}{2} \alpha_{13}-\frac{1}{2} \alpha_{32}-\frac{1}{2} \alpha_{23}\right)\right\|\left(N_{3}-\overline{N_{3}}\right)^{2}-\frac{1}{2}\left\|\left(\alpha_{31}+\alpha_{13}\right)\right\| \\
& V^{1}(t) \leq-\mu \sum_{i=1}^{3}\left[N_{i}-\overline{N_{i}}\right]^{2}<0 \\
& \text { Where } \mu=\min \left(\begin{array}{l}
\alpha_{11}+\alpha_{22}+\alpha_{33}+\frac{1}{2} \alpha_{13} \\
+\frac{1}{2} \alpha_{31}+\frac{1}{2} \alpha_{21}-\frac{1}{2} \alpha_{12} \\
-\frac{1}{2}\left(\alpha_{31}+\alpha_{13}\right)
\end{array}\right)
\end{aligned}
$$$$
\frac{d V}{d t}<0
$$

Therefore the system is globally stable at interior equilibrium $E_{1}\left(\overline{N_{1}}, \overline{N_{2}}, \overline{N_{3}}\right)$

\section{NUMERICAL EXAMPLE}

\section{Graphs Description:}

\begin{tabular}{|l|l|l|}
\hline S.No & Figures & \multicolumn{1}{c|}{ Description } \\
\hline 1 & $\begin{array}{l}\text { The } \\
\text { figures(A) }\end{array}$ & $\begin{array}{l}\text { Shows the variation of } \mathrm{N}_{1}, \mathrm{~N}_{2} \text { and } \mathrm{N}_{3} \\
\text { with respect to Time }(\mathrm{t})\end{array}$ \\
\hline 2 & $\begin{array}{l}\text { The } \\
\text { figures(B) }\end{array}$ & The phase portrait of $\mathrm{N}_{1}, \mathrm{~N}_{2}$ and $\mathrm{N}_{3}$ \\
\hline
\end{tabular}

Example 1: Let $\mathrm{a}_{1}=6, \alpha_{11}=0.01, \alpha_{12}=0.45, \alpha_{13}=0.3, \mathrm{a}_{2}=2.5$, $\alpha_{21}=0.43, \quad \alpha_{22}=0.1, \quad \alpha_{23}=0.32, \quad a_{3}=3, \quad \alpha_{31}=0.01, \quad \alpha_{32}=0.12$, $\alpha_{33}=0.23, \mathrm{~d}_{1}=0.02, \mathrm{~d}_{2}=0.02$, $\mathrm{d}_{3}=0.03, \mathrm{~N} 1=15, \mathrm{~N}_{2}=15, \mathrm{~N}_{3}$ $=15$. 
The systems of equations (2.1) are simulated using MATLAB using ode 45.The system of equations without delay is solved with the same package we get the following results illustrated by the graphs 6.1(A), 6.1(B) for the following parametric values:

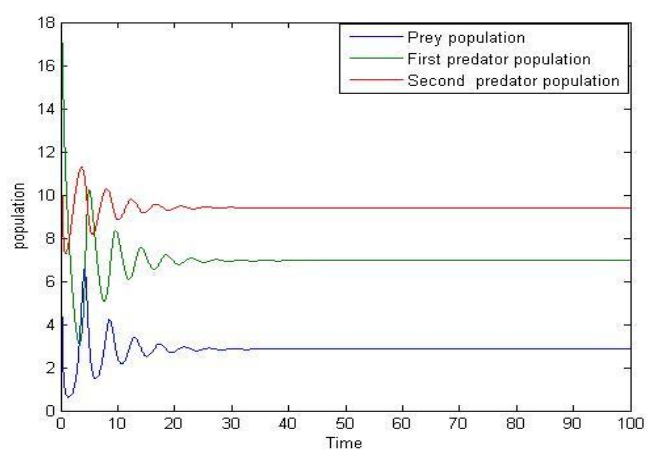

Fig:6. 1(A)

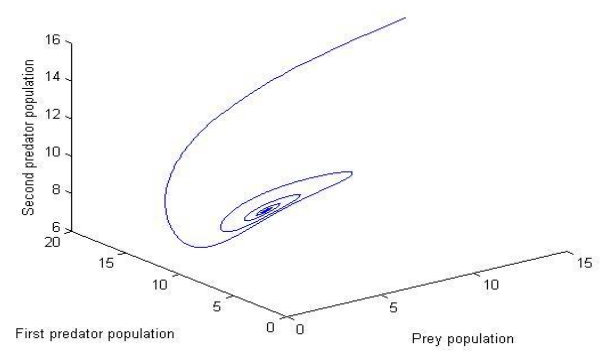

Fig: 6.1(B)

For the above mentioned parametric values, the three populations asymptotic to the fixed equilibrium point $\mathrm{E}$ (3, $7,10)$. Hence the system is asymptotically stable.
Exponential function is given

$$
k_{1}(z)=k_{2}(z)=a e^{-a z} \text { for } a>0
$$

Then the Laplace transform of $k_{1}(z) \& k_{2}(z)$ are defined as $k_{1}(\lambda)=k_{2}(\lambda)=\int_{0}^{\infty} e^{-\lambda t} a e^{-a t} d t=\frac{a}{a+\lambda}$

The results are simulated for the above system of equations (2.3) Using MAT LAB simulation with the parameters shown in Example 1 with different kernel values are plotted below.

1. $\lambda=0.5, a=5 \mathrm{E}(3,8,9)$

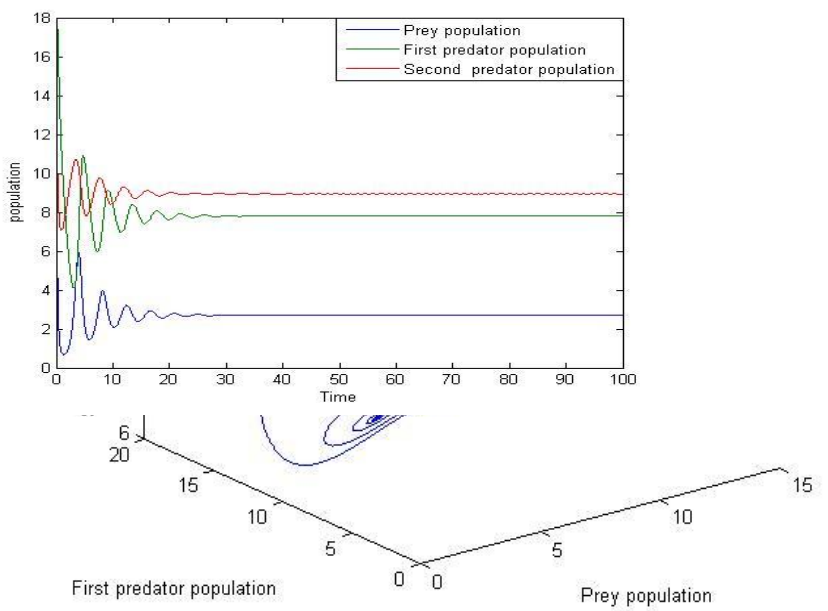

Fig: 6.2(A)

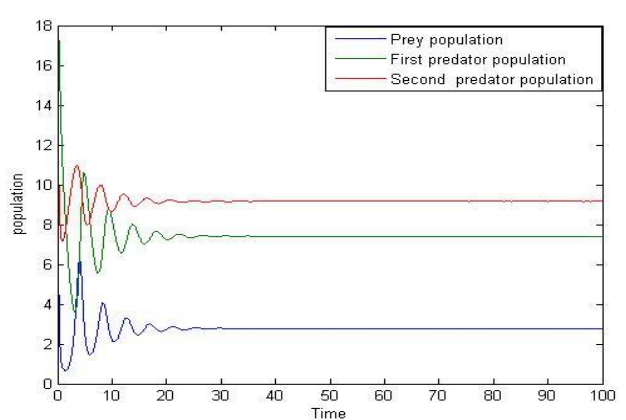

Fig: 6.2(B)

The system is asymptotically stable to a fixed equilibrium point $\mathrm{E}(3,8,9)$.For fixed value of $\lambda=0.5$, as on a value increases from 1 to 100 , still the system is asymptotically stable to the fixed equilibrium point. For $\lambda=0.5, \mathrm{a}=150$, the system is asymptotic to a fixed equilibrium $\mathrm{E}(3,7,10)$. 2. $\lambda=10, a=0.5 \mathrm{E}(3,8,10)$

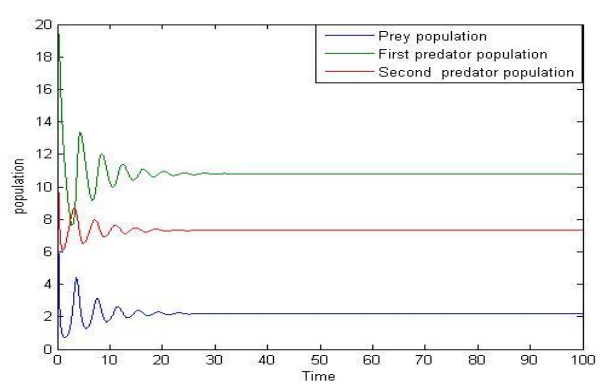

Fig: 6.3(A)

The system is asymptotically stable to a fixed equilibrium point $\mathrm{E}(3,8,10)$. For fixed value of $\lambda=10$, as on a value

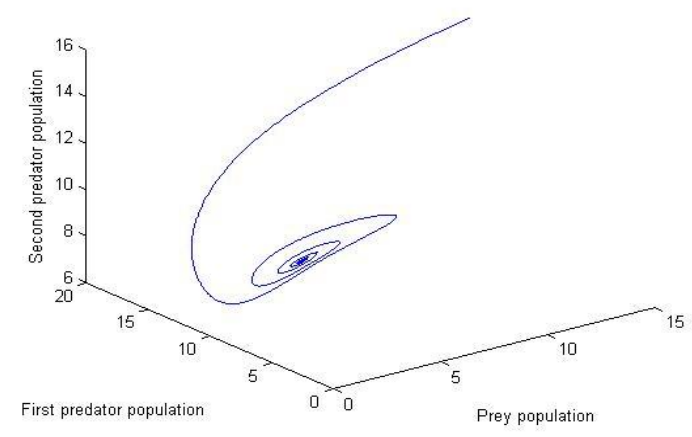

increases from 1 to 100 , still the system is asymptotically stable to the fixed equilibrium point. For $\lambda=10, a=150$, the system is asymptotic to a fixed equilibrium $\mathrm{E}(2,13,7)$ 3. $\lambda=0.5, a=0.5 \mathrm{E}(3,11,8)$ 


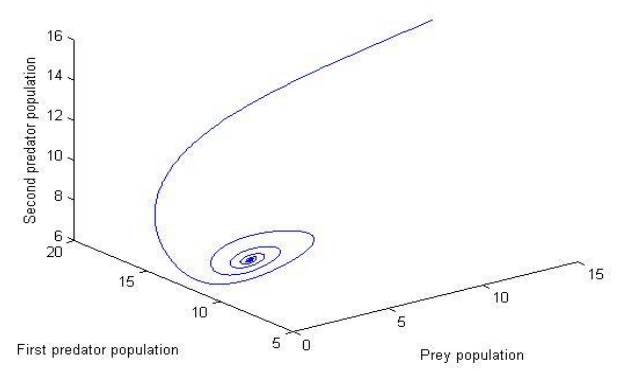

Fig: 6.4(B)

The system is asymptotically stable to a fixed equilibrium point $\mathrm{E}(3,11,8)$

4. $\lambda=0.5, \mathrm{a}=1 \mathrm{E}(3,9,9)$

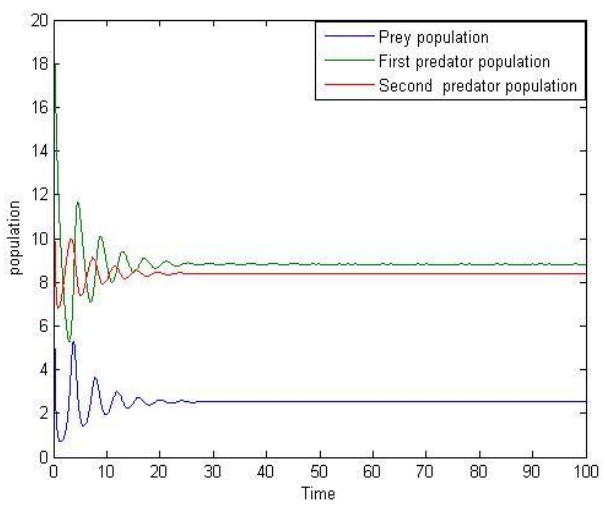

Fig: 6.5(A)

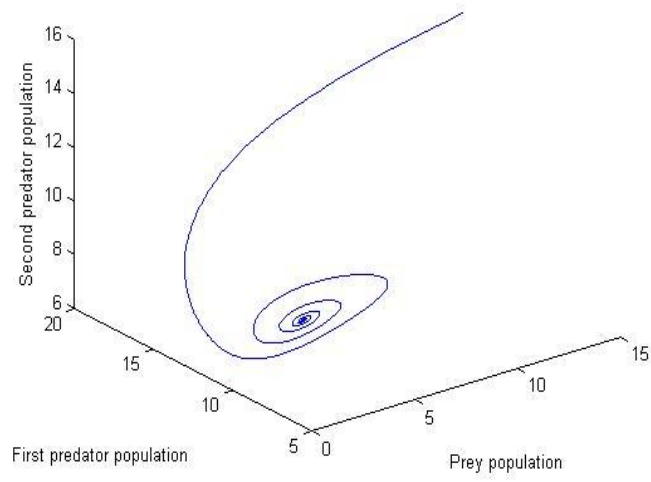

Fig: 6.5(B)

The system is asymptotically stable to a fixed equilibrium point $\mathrm{E}(3,9,9)$

\section{CONCLUSION}

A three species ecological model with a single prey and two Predators is considered for investigation. Here two predators are competing for the same Prey. The time delay is imposed on the prey and second predator species. The co-existing state is identified. The systemis asymptotically stability. The global stability is studied by Lxapunoy's function. The dynamics of the system is studied using numerical simulation in support of stability analysis. We consider numerical example with delay and without delay agreements. The system is asymptotically stable if there is no delay impact. The impact of delay with different kemel strength is studied and observed that thesxstems are asymptotically stable, exhibit periodic solutions and limit cycles. For (i) $\lambda=10, a=$ 150 (ii) $\lambda=0.5, a=0.5$ (iii) $\lambda=0.5, a=1$, there is a significant growth in the first predator population. So delay play a significant role in system dynamics.

\section{REFERENCES}

1. G Lotka. A.J.: Elements of physical biology, Williams and Wilkins, Baltimore, 1925.

2. Volterra, V: Leconssen la theoriemathematique de la leitte pou lavie, Gauthier-Villars, Paris,1931.

3. Kapur, J.N.: Mathematical Modeling, Wiley-Eatern, 1988.

4. Kapur,J.N. :Mathematical Models in Biology and Medicine, Affiliated East-west, 1985.

5. May, R.M.: Stability and complexity in model Eco-Systems, Princeton University press, Princeton, 1973.

6. Freedman.H.I.: Deterministic mathematical models in population ecology, Marcel-Decker, New York,1980.

7. Paul colinvaux.: Ecology, John Wiley and Sons Inc., New York, 1986.

8. Braun.M.: Differential equations and their applications- Applied Mathematical Sciences, (15) Springer, New York, 1978.

9. George F.Simmons.: Differential Equations with Applications and Historical notes, Tata Mc.Graw-Hill, NewDelhi, 1974.

Cushing, J.M.: Integro-Differential equations and delay models in population dynamics, Lect. notes in biomathematics, vol(20),Springer-Verlag, Heidelberg, 1977

10. V.SreeHariRao and P. Raja SekharaRao, Dynamic Models and Control of Biological Systems, Springer Dordrecht Heidelberg London New York, 2009

11. Gopalaswamy, K: Mathematics and Its ApplicationsStability and Oscillations in Delay Differential Equations of Population Dynamics Kluwer Academic Publishers, 1992.

12. Papa Rao A.V., Lakshmi Narayan K., A prey, predator and a competitor to the predator model with time delay ,International Journal of Research In Science \& Engineering, Special Issue March Pp 27-38 ,2017.

13. Papa Rao A.V., Lakshmi Narayan K.,Dynamics of Three Species Ecological Model with Time-Delay in Prey and Predator, Journal of Calcutta Mathematical society, vol 11,No 2, Pp.111-136, 2015.

14. Papa Rao A.V., Lakshmi Narayan K.,Dynamics of Three Species Ecological Model with a Prey, predator and competitor, Bulletin of Calcutta Mathematical society, Vol 108 No.6 Pp.465-474,2016.

15. Papa Rao A.V., Lakshmi Narayan K.,Dynamics of Prey predator and competitor model with time delay, International Journal of Ecology\& Development, Vol 32, Issue No. 1 Pp 75-86, 2017.

16. Papa Rao A.V., Lakshmi Narayan K., Optimal Harvesting of Prey in Three Species Ecological Model with a Time Delay on Prey and Predator ,Research Journal of Science and Technology, vol:9 issue 03,2017 . 


\section{AUTHORS PROFILE}

Dr. B.Sitarambabu completed his Ph.D from JNTUH, Hyderabad. He has 17 years of teaching Experience. Presently He is working as a Professor of Mathematics in VIDYAJYOTHI Institute of Technology, Hyderabad. He published more than 17 research articles in reputed Journals and He attended and presented more than 18 National/ International Conferences. His area of research is Mathematical Modeling like Mathematical Ecology, Epidemiology and Pharmacokinetics.

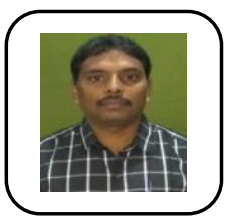

Dr. Papa Rao. A. V. completed his Ph.D from JNTUK Kakinada. He has 15 years of teaching Experience. Presently $\mathrm{He}$ is working as an Assistant Professor of Mathematics in JNTUK University college of Engineering Vizianagaram Campus. He published more than 30 research articles in reputed Journals and He attended and presented more than 30 National/ International Conferences. His area of research is Mathematical Modeling like Mathematical Ecology, Epidemiology and Pharmacokinetics. Presently he is guiding $3 \mathrm{Ph}$. D Scholars.

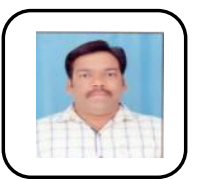

NVSRC MURTY GAMINI working as Associate Professor in Mathematics since 2006, in BVC Institute of technology, Batlapalem, Amalapuram-533201. And pursuing Ph.D. in JNTUK with specialisation 'Mathematical Modelling". Completed M.Tech.(Computer Science and Engineering.) and M.Sc. in Mathematics \& Computer Science. 